\title{
Incremental Direct Medical Costs of Systemic Lupus Erythematosus Patients in the Years Preceding Diagnosis: A General Population-Based Study
}

Natalie McCormick ${ }^{1,2}$, Carlo A. Marra ${ }^{1,2,3}$, Mohsen Sadatsafavi ${ }^{1}$, J. Antonio Aviña-Zubieta ${ }^{2,4}$

${ }^{1}$ Faculty of Pharmaceutical Sciences, The University of British Columbia, Vancouver, BC, Canada

${ }^{2}$ Arthritis Research Canada, Richmond, BC, Canada

${ }^{3}$ School of Pharmacy, University of Otago, Dunedin, New Zealand

${ }^{4}$ Division of Rheumatology, Department of Medicine, The University of British Columbia, Vancouver, BC, Canada

Running Head: Healthcare Costs of SLE Patients Before Diagnosis

Corresponding Author:

Dr. J. Antonio Aviña-Zubieta

5591 No. 3 Road, Richmond BC Canada V6X 2C7

Phone: 604-207-4041; e-mail: azubieta@arthritisresearch.ca

Keywords: systemic lupus erythematosus; direct medical costs; health resource utilisation; sex differences; socioeconomic status; cardiovascular disease

Word Count: 3,914 (excluding title page, abstract, references, figures and tables) 


\section{ABSTRACT}

\section{Objective}

We estimated the incremental (extra) direct medical costs of a population-based cohort of newlydiagnosed systemic lupus erythematosus (SLE) for five years before and after diagnosis, and the impact of sex and socioeconomic status (SES) on pre-index costs for SLE.

\section{Methods}

We identified all adults newly-diagnosed with SLE over 2001-2010 in British Columbia, Canada, and obtained a sample of non-SLE from the general population, matched on sex, age, and calendar-year of study entry. We captured costs for all outpatient encounters, hospitalisations, and dispensed medications each year.

Using generalised linear models, we estimated incremental costs of SLE each year before/after diagnosis (difference in costs between SLE and non-SLE, controlling for covariates). Similar models were used to examine the impact of sex and SES on costs within SLE.

\section{Results}

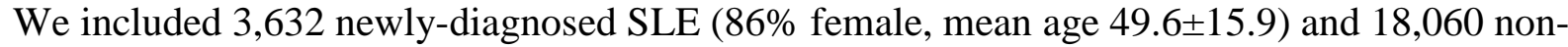
SLE individuals. Over the five years leading up to diagnosis, per-person healthcare costs for SLE patients increased year-over-year by 35\%, on-average, with the biggest increases in the final two years: by 39\% and 97\%, respectively. Per-person all-cause medical costs for SLE the year after diagnosis (Year +1) averaged \$12,019 (2013 Canadian) with 58\% from hospitalisations, 24\% outpatient, and 18\% from prescription medications; Year +1 costs for non-SLE averaged \$2,412. Following adjustment for age, sex, urban/rural residence, socioeconomic status, and prior year's comorbidity score, SLE was associated with significantly greater hospitalisation, outpatient, and 
medication costs than non-SLE in each year of study. Altogether, adjusted incremental costs of SLE rose from \$1,131 per-person in Year -5 (fifth year before diagnosis) to \$2,015 (Year -2), \$3,473 (Year -1), and \$6,474 (Year +1).

In Years $-2,-1$, and +1 , SLE patients in the lowest-SES group had significantly-greater costs than the highest-SES. Unlike the non-SLE cohort, male patients with SLE had higher costs than females. Annual incremental costs of SLE males (versus SLE females) rose from \$540 perperson in Year -2, to \$1,385 in Year -1, and \$2,288 in Year +1 .

\section{Conclusion}

Even years before diagnosis, SLE patients incur significantly-elevated direct medical costs than the age- and sex-matched general population, for hospitalisations, outpatient care, and medications. 


\section{INTRODUCTION}

According to a recent systematic review(1), about three of every 100,000 North Americans are diagnosed with systemic lupus erythematosus (SLE) each year, and up to six per100,000 Europeans. This disease tends to start slowly and insidiously, with SLE-associated autoantibodies present many years(2,3) before symptom-onset or diagnosis. Though complete SLE is characterised by intense inflammation, organ damage, and a high comorbidity burden, the early manifestations are often non-specific, typically involving arthritis(4,5) and photosensitivity(4), which makes diagnosis difficult.

The time from initial symptoms to formal diagnosis (accumulation of four American College of Rheumatology (ACR) Classification Criteria(6)) spans, on average, two years(7), but can be longer without the classic malar rash or symptoms suggestive of life-threatening organ involvement(5). During this time, however, the inflammatory effects of SLE are already setting in. Evidence suggests there is an elevated risk of cardiovascular disease(8) during this period and, by the time of diagnosis, many patients already have renal disease $(9,10)$, including nephritis(11,12).

The investigation of initial symptoms and management of serious health events preceding diagnosis is likely associated with additional medical costs. However, while several estimates are available on the costs of SLE patients following diagnosis(13-15), little is known about the years prior. Two recent analyses of primary care data in the United Kingdom (UK) reported substantial increases (65\%(16) and 71\%(17)) in primary care visits between the second and first year prior to SLE diagnosis. In the only report we could find on healthcare costs before diagnosis, which 
described the pre-diagnosis (pre-index) cost patterns in Taiwan(18), mean per-person costs for outpatient care more than doubled from the fifth to first year before diagnosis. Unfortunately, that study did not assess hospitalisation or medication costs, and their findings may not be generalisable to other countries or healthcare systems. Moreover, the impact of factors like socioeconomic status (SES) and sex on pre-index costs is also unknown. These are of interest since lower SES has been associated with reduced access to care and poorer outcomes(19) lateron in the disease course, and males tend to accrue damage more quickly than females(20).

Knowledge of the pre-index healthcare utilisation and costs of SLE patients across multiple settings, not just primary care, would give policymakers more information about the real burden of this disease. It would also inform emerging strategies to expedite diagnosis and initiation of treatment, and even slow(21) or prevent the development of complete SLE in those at high risk(22), with pre-emptive hydroxychloroquine therapy.

To generate such knowledge, we used routinely-collected administrative healthcare data from a single-payer setting capturing the entire population to estimate the incremental healthcare burden of SLE in the five years before diagnosis, and year following, and assess the impact of sex and socioeconomic status on costs. 


\section{METHODS}

\section{Data source}

The province of British Columbia (BC), Canada, has a publicly-funded, universal healthcare system through which all legal residents receive medically-necessary outpatient and hospital care. The administrative data were sourced through Population Data BC, which uses population-based linkable administrative data files to capture records of all provincially-funded healthcare services, including all outpatient medical visits, interventions, and investigations(23), and hospitalisations(24), from 1990 through 2013, as well as demographic(25) and vital statistics data(26). Furthermore, it includes data on nearly all community-dispensed prescription medications for all BC residents (population of 3.5 million adults in year 2010), regardless of age or funding source, from 1996 through 2013(27). Numerous general population-based studies have been successfully conducted using these databases(28-30). Ethics approval was obtained from the Behavioral Research Ethics Board at The University of British Columbia [H12-03093]. As this was an analysis of de-identified data, participant consent was not required.

\section{Study populations}

From the administrative data files, we assembled a population-based cohort of all BC adults (aged $\geq 18$ years) newly-diagnosed with SLE from January 1, 2001 through December 31, 2010. SLE cases were identified using International Classification of Diseases Ninth/Tenth (ICD-9/10) Revision diagnostic codes (710.0/M32) recorded for outpatient encounters and hospitalisations as follows: (a) $\geq$ two ICD-9 codes for SLE $\geq$ two months apart but within a twoyear period by a non-rheumatologist physician (excluding codes recorded for laboratory tests and other diagnostic encounters); or (b) one ICD-9 code by a rheumatologist; or (c) one ICD-9/10 
code from a hospitalisation. The code could have been in any of the five diagnostic positions in the outpatient billing data or in any of the up to 25 positions in the hospitalisation data. The first SLE-coded encounter was considered the index date. Potential cases were excluded if they had at least two visits $\geq$ two months apart (subsequent to the SLE index encounter) with diagnoses of other inflammatory arthritides, including rheumatoid arthritis, psoriatic arthritis, and spondyloarthropathies. The validity of this case definition has been evaluated in another Canadian province with reported sensitivity of $85 \%$ and specificity of $98 \%(31)$.

The non-SLE group was selected from a random sample of the BC population whom we randomly-assigned an index date among all possible dates within the study period. Those whose random date fell outside of their actual follow-up (i.e. after their death) were eliminated. From this pool, we selected up to five individuals per SLE case, matched on age ( \pm two years), sex, and calendar-year of study entry, and eliminated any with an SLE diagnosis.

\section{Healthcare utilisation and costs}

To ensure only incident cases were included, all individuals (SLE and non-SLE) needed at least five years of registration in the databases prior to meeting the case definition for SLE. This 'run-in' period also ensured we had complete healthcare utilisation and cost data for the preceding five years. Thus, all healthcare utilisations captured in the databases from five years prior to index date and for up to five years after index date (or until the earliest of death, deregistration from BC’s universal health insurance provider, or December 31, 2013) were included, and unit costs summed. Though this article focusses on the pre-index period, costs were computed from Year -5 (fifth year before diagnosis) through Year +5 (fifth year after 
diagnosis) to provide evidence on the change in costs after diagnosis. Costs were computed in accordance with guidelines issued by Canada's health technology assessment agency, the Canadian Agency for Drugs and Technologies in Health(32). The unit cost of each outpatient encounter (available in the dataset) was the amount paid to health care providers by the BC Ministry of Health. The costs for each prescription (also available in the dataset) included the complete drug cost and dispensing fee. Costs for inpatient and day hospitalisations were calculated using the Canadian Institute for Health Information (CIHI)'s well-established casemix methodology(32), in which the resource intensity weight (RIW) of each hospitalisation (provided by CIHI), the relative resource consumption of that particular hospitalisation in relation to the provincial 'standard' (for which the RIW would equal 1.0), is multiplied by the cost of a standard hospital stay in the province each year. All costs were adjusted for inflation using the general component of the Canadian Consumer Price Index. Costs are reported primarily in 2013 Canadian dollars, though for comparison purposes, we also show some estimates converted to 2013 Euros ( $\$ 1 \mathrm{CDN}=€ 1.3681)$ and US dollars $(\$ 1 \mathrm{CDN}=1.0299148$ USD), using exchange rates from the Bank of Canada.

\section{Independent variables}

A modified version of the Charlson-Romano comorbidity index for administrative data(33), one excluding diagnoses of SLE and other systemic autoimmune rheumatic diseases, was calculated for each 365-day period before index date, and collapsed into categories of 0 or $\geq$ 1. For example, when assessing costs incurred during the final 365 days before SLE diagnosis (Year -1), we adjusted for comorbidities recorded during the second 365-day period before diagnosis (Year -2). 
SES was defined using Statistics Canada neighbourhood income quintile data, as per previous analyses(29,30). SES was grouped according to the income quintile of the address recorded for each individual (by the provincial medical plan) in each study year. Urban/rural residence was defined using the first three digits of the postal code of this address (second-digit of 0 indicating a rural address).

\section{Statistical analysis}

Unadjusted comparisons between SLE and non-SLE individuals (and between male and female SLE) were made using chi-squared tests and $t$-tests. Mean per-person healthcare use and costs for each year (365-day period) were then determined for the (pre)-SLE and non-SLE cohorts. Multivariable generalised linear models (GLM), adjusted for sex, age at index year, and year-specific comorbidity score, urban/rural residence, and SES, were then used to determine the relative utilisation and costs associated with SLE each year. Negative binomial count models were used to compare volumes of outpatient encounters and dispensed medications. Log-link and gamma distribution were specified in the cost models to account for skewness in these data(34).

The unit of analysis was person-year of follow-up. Thus, separate regression models were constructed for each year before diagnosis/index date and the year after. Pre-index follow-up time was the same for all individuals (five full years), but post-index follow-up time could be less than one year for some individuals who might have died or reached the end of the study period. To account for this, an offset variable (log of each person's follow-up time) was used in the count models, while the post-index cost models only included individuals followed for the entire post-index year. As some individuals did not incur healthcare costs during each follow-up 
year, two-part models(34) were used for cost calculation. The first part (a logistic regression model) assessed one's probability of incurring any healthcare costs that year, controlling for covariates, while the second part (a gamma GLM) assessed costs only among those with nonzero costs. Similar models assessed the impact of sex and SES on costs within the SLE cohort.

To derive the incremental costs, which is the difference in costs between the SLE and the comparison group from the two-part model, we used G-computation(35), as has been applied previously on these data(30). With this approach, multivariable regression models are used to predict costs for each individual multiple times, each time with the same person in a different disease or sociodemographic group, but with their other covariates the same. The difference between estimates (i.e. predicted costs as if the same person did and did not have SLE) represented the incremental costs when the status of the variable changed (i.e. an individual was in the non-SLE or the SLE group), and per-person incremental costs were averaged across all individuals followed each year, with 95\% credible intervals derived through parametric bootstrapping. Analyses were generated using the SAS Enterprise software package, version 7.13. 


\section{RESULTS}

We identified 3,632 newly-diagnosed SLE patients for the years 2001-2010 (86\% female, mean age 49.6 \pm 15.9 ) and 18,060 non-SLE individuals (mean age 49.8 \pm 15.4 ). Two-thirds of SLE were diagnosed by a rheumatologist on an outpatient basis, with an additional $20 \%$ diagnosed in hospital (Table 1). SLE males were slightly older, on average, than SLE females (49.1 vs. 52.9 years, $\mathrm{p}<0.01$ ), as were non-SLE males and females, and males had a higher comorbidity score at diagnosis. Otherwise, males and females were nearly identical with regards to urban/rural residence, SES distribution, and source of SLE diagnosis

Costs for SLE in first year after diagnosis (Year +1) averaged \$12,019 per-person (2013 Canadian; approximately $€ 16443$ or $\$ 12,378$ USD) with 58\% from hospitalisations, 24\% outpatient, and 18\% from prescription medications. Mean per-person costs for non-SLE were about five-fold lower, \$2,412 per-person (€3300; \$2,484 USD). In the five years leading up to diagnosis, the average year-over-year increase in costs was 35\% for the SLE cohort and 7\% for non-SLE. However, the largest annual increases for SLE were observed in the final two years before diagnosis: 39\% and 97\%, respectively (Table 2).

After adjustment for sex, age, urban/rural residence, SES, and comorbidity burden in the preceding year, costs were significantly greater for SLE than non-SLE each year (Table 3). Incremental costs of SLE (difference in costs between SLE and non-SLE, controlling for covariates) rose over time from $\$ 1,131$ in Year -5 (€1547; \$1,165 USD) to \$1,536 in Year -3 (€2101; \$1,582 USD), \$3,473 in Year -1 (€4751; \$3,577 USD), and \$6,474 (€8857; \$6,668 USD) in the year after SLE diagnosis (Table 2). 


\section{Healthcare Components}

During the final two years before diagnosis, costs for outpatient consultations and investigations rose by 39\% and 35\%, respectively (Figure 1). For outpatient investigations specifically, the biggest increase occurred between Years -2 and -1 (by 47\%, from $\$ 468$ to $\$ 690$ per-person; equal to €640-944 and \$482-711 USD). Prescription medication costs increased the most (by 33\%) between Years -1 and +1 . The percentage of SLE with an inpatient hospitalisation was $10-12 \%$ in Years -5 to $-2,18 \%$ in the year before diagnosis, and $31 \%$ the year after, while only 6-7\% of non-SLE were hospitalised each year. Day hospitalisations accounted for just 2-4\% of annual costs.

The median number of physician consultations increased from 9 (IQR=4-16) in Year -5, to 11 (IQR=6-20) in Year -2, 15 (IQR=9-25) in Year -1, and 18 (IQR=11-30) in Year +1. For general practitioners (GPs) specifically, median consultations for SLE were $6(\mathrm{IQR}=3-12)$ in Year -5, 8 (IQR=4-14) in Year -2, and 10 in Years -1 and +1; non-SLE had a median of 5 GP consultations in each of these years. Thirty-four percent of those eventually diagnosed with SLE visited a rheumatologist in the year before SLE diagnosis, and 84\% the year after.

\section{Impact of sex}

Starting from Year -4, unadjusted annual mean per-person costs for SLE males were about 25\% greater than SLE females (Figure 2). In the year after SLE diagnosis, their costs were 68\% greater ( $\$ 18,433$ vs. \$10,945 CDN) (€25 218 vs. $€ 14$ 974; $\$ 18,984$ vs $\$ 11,272$ USD). Following adjustment, male sex was associated with significantly-greater costs among SLE in Years -2 , -1 , and +1 (Table 4). Hospitalisations were a major contributor, with males having 
greater odds of hospitalisation than females in the year before diagnosis (odds ratio $(\mathrm{OR})=1.49$, 95\% CI=1.19-1.88), and significantly-greater hospitalisation costs the year after. Conversely, among non-SLE, male sex was associated with significantly lower costs over Years -5 to +1 . In absolute terms, predicted incremental costs for SLE males (over-and-above SLE females') were \$540 per-person in Year -2 (€739; \$556 USD), \$1,385 in Year -1 (€1895; \$1,426 USD), and \$2,288 in Year +1 (€3130; \$2,356 USD).

\section{Impact of socioeconomic status}

Among SLE, being in the lowest-SES group was associated with significantly-greater healthcare costs in Years $-4,-2,-1$, and +1 (Table 4). The second-lowest group also had significantly-greater costs in Years -2 and +1 . Outpatient costs contributed, but hospitalisations were the major driver in Year +1 . The lowest-SES had greater odds of being diagnosed in hospital ( $\mathrm{OR}=1.45,1.12-1.88)$, and, as compared to others diagnosed in hospital, incurred greater costs for this index hospitalisation (adjusted cost ratio=1.33, 1.05-1.68). 


\section{$\underline{\text { DISCUSSION }}$}

To the best of our knowledge, these are the first-known estimates of outpatient, hospitalisation, and medication costs before SLE diagnosis. With access to routinely-collected healthcare utilisation data for virtually all residents of our jurisdiction, we assessed the incremental costs among 3,632 SLE patients before and after diagnosis. Though index-year costs were nearly four-times greater for SLE than the non-SLE group, SLE patients had significantlygreater costs for all of these components, during each of the five years before diagnosis.

The largest increases in utilisation and costs occurred in the two years before diagnosis, which is consistent with oft-reported span of two years, on-average, from symptom onset to SLE diagnosis(7). However, individuals with SLE also incurred greater costs than non-SLE in the third, fourth, and fifth years before diagnosis, and had more comorbidities recorded in the preindex period. These findings suggest the rise in incremental costs over time is not solely from consultations and investigations involved in confirming the diagnosis, and rather indicate the broader, systemic aspect of inflammation affecting multiple organs.

Though our findings may not be generalisable to SLE patients in all countries or healthcare settings, they are consistent with previous, more limited assessments of pre-index use and costs in SLE. Two studies were conducted using primary care data from the UK Clinical Practice Research Datalink. In one(17), the median number of primary care visits for SLE patients increased from six per-year (Years -5, -4, and -3) to seven (Year -2), and 12 in the year before diagnosis. Conversely, visits for the non-SLE comparison group (median 3) were unchanged(17). The second UK study(16) reported an increase in median annual consultations 
from one ( 4 to 4.5 years before diagnosis, IQR=0-17), to 23 in Year -2 (IQR=11-43), and 38 in Year -1 (IQR=23-61). A third study, conducted in Taiwan(18), found that pre-index outpatient costs were significantly greater for SLE than non-SLE, even for eight years before diagnosis. The annual median number of ambulatory care encounters was significantly greater for SLE each year, and rose from 1 (Year -8) to 11 (Year -5), 13 (Year -2), and 22 in Year -1(18). Similar findings on incremental pre-index costs have been reported for rheumatoid arthritis (RA) patients in Taiwan(36), and psoriatic arthritis(37) and RA(38) patients in Denmark. In the latter study, costs for RA patients were significantly-greater than the general populations', even 11 years before diagnosis.

Despite our having a publicly-funded healthcare system covering all BC residents, we found that low SES was independently associated with increased healthcare costs, especially in the final two years before diagnosis. Specifically, the lowest-SES group had greater outpatient costs than the highest-SES, were more likely to be diagnosed in-hospital, and incurred greater hospitalisation costs at diagnosis. Since there are no private acute-care hospitals in BC, these differences in hospitalisation rates and costs cannot be attributed to the highest-SES patients obtaining care outside the public system. It is possible, however, that the lowest-SES individuals face difficulties in accessing care that eventually land them in hospital at the time of diagnosis, requiring more complex care. Low household income has been associated with delayed presentation to rheumatology care among paediatric SLE patients in the United States(39), something that warrants further exploration in adult SLE. However, it may be less of an issue within Canada's single-payer system where access to primary and specialist care is more universal. 
Another striking finding was SLE males having significantly-higher costs than SLE females in this period, even after adjustment for age, urban/rural residence, and SES. Unlike the SES groups, males and females were quite similar regarding the sources of diagnosis; however, SLE males did have a significantly-higher pre-index comorbidity burden than females. There is disagreement in the literature about whether males (particularly Caucasians) tend to be diagnosed at an older age than females, and have a different, perhaps more severe, form of lupus with associated increased mortality(40). But it has been reported that males are more likely to have renal disease at SLE diagnosis(9,10), and accrue more organ damage than females(10,20). Evidence also suggests that, among those with confirmed SLE, cardiovascular disease/damage is higher in males(41-43). If males also have more organ damage and comorbidities in the preindex period, this may explain why pre-index healthcare costs were higher for males. Although costs in each pre-index year (and Year +1 ) were adjusted for the Charlson-Romano comorbidity score for the previous 365-days, there may have been residual differences in comorbidity burden between the sexes.

Though sex-specific data on pre-index comorbidities in SLE are not available, evidence does suggest that, overall, SLE patients have an increased inflammatory disease burden before diagnosis. In clinical studies, many patients have had nephritis(11,12) or other forms of renal disease $(9,10)$ at diagnosis, and while SLE patients are known to have an elevated risk of cardiovascular events immediately following diagnosis(28), increased cardiovascular disease before SLE diagnosis has also been reported. Among members of the multinational SLICC cohort, prevalence of myocardial infarction around the time of SLE diagnosis (between five years before, and two years following) exceeded the figure reported for the general population 
(4.8\% vs. $0.7 \%)(44)$. In a population-based study in rural Wisconsin, USA, SLE patients had 3.8-times greater odds of cardiovascular disease in the two years prior to diagnosis, versus a sexand age-matched sample from the general population. This included three-times greater odds of both heart failure and ischaemic heart disease, and five-times greater odds of stroke(8). Increased cardiovascular disease has also been observed in the years preceding diagnosis of RA $(45,46)$ and psoriatic arthritis(37), and diabetes has been associated with subsequent diagnosis of RA(47,48).

Several mechanisms have been proposed for the concurrence of SLE and these other inflammatory diseases. As mentioned by the SLICC investigators, early autoimmunity and early atherosclerosis may develop at the same time, but through independent processes(44); alternatively, early subclinical autoimmunity may actually contribute to early subclinical atherosclerosis(44). The Wisconsin investigators suggested that atherosclerosis may accelerate prior to full onset of SLE, but also acknowledged that formal diagnosis of SLE may have been delayed in their cohort due to its older age, rural nature, and higher percentage of males(8). Renal disease, meanwhile, is likely an early manifestation of undiagnosed (or unconfirmed) SLE in itself.

We expect our novel estimates will inform current healthcare decision-making, and efforts to expedite SLE diagnosis and treatment, or, in high-risk individuals, even prevent it from developing. One early or potentially pre-emptive treatment is hydroxychloroquine (HCQ). Persistent use of HCQ in newly-diagnosed patients has been associated with a longer clinically quiescent phase(49), and early initiation of HCQ (after initial symptoms, but before accumulation of $\geq$ four ACR criteria) has been shown to delay the accumulation of additional 
criteria(21). Moreover, these efforts could be cost-saving: a retrospective analysis of US commercial claims data(50) found that 'early' diagnosis of SLE (within six months of symptom onset) was associated with fewer flares, and lower levels of post-diagnosis healthcare costs, compared to those diagnosed 6-12 months after symptom onset. However, the possible harms and added costs of any early treatment efforts (including the consequences of treating falsepositive cases of SLE) warrant careful evaluation.

Our administrative healthcare data imparted both strengths and limitations to this analysis. Although SLE patients were identified from ICD codes, and the diagnoses were not clinically confirmed, $86 \%$ were identified by a rheumatologist or hospitalisation, and our case definition has a reported specificity of $98 \%$ and positive predictive value of $91 \%$ in the Canadian setting(31). Moreover, we helped ensure only truly incident SLE were included by requiring five years' pre-index follow-up time without meeting the case definition for SLE. As we did not have access to medical records, we could not assess whether the SLE index date coincided with patients' fulfilling at least four ACR classification criteria, but the temporal cost patterns we observed (costs rising in the final two years before diagnosis, and peaking the year after diagnosis) do lend support and are consistent with previous reports $(17,18)$.

Despite these limitations, our routinely collected data allowed us to identify virtually all newly-diagnosed SLE in the province (regardless of age, employment, urban/rural residence, or disease severity) and capture their pre-index healthcare utilisation from all settings (not just primary care) with minimal selection and recall bias. Our estimates include the costs for all provincially-funded outpatient encounters and hospitalisations, and virtually all community- 
dispensed prescriptions, regardless of age or funding. However, we acknowledge our estimates do not include items not captured in the databases (and not funded by the province) such as nonprescription medications and most allied health visits.

In this population-based analysis, the healthcare and economic impact of SLE was evident long before the diagnosis was recorded. Even in the fifth year before diagnosis, members of the SLE cohort were more likely to be hospitalised than non-SLE, and incurred greater direct medical costs: \$1,131 more per-person, on-average. We hope this work will increase recognition of the early healthcare costs of SLE, including the impact of low socioeconomic status and early comorbidities, and spur efforts to mitigate this burden. 


\section{ACKNOWLEDGEMENTS}

We would like to thank Dr. Wenjia Chen for her assistance with the statistical analysis. All inferences, opinions, and conclusions drawn in this manuscript are those of the authors, and do not reflect the opinions or policies of the Data Steward(s).

\section{DECLARATION OF CONFLICTING INTERESTS}

The Authors declare that there is no conflict of interest.

\section{FUNDING}

This work was supported by the Canadian Arthritis Network/The Arthritis Society of Canada [grant number 10-SRP-IJD-01]; and the Canadian Institutes of Health Research [grant number THC-135235]. N.M. held a Doctoral Research Award from the Canadian Institutes of Health Research. M.S. holds a Scholar Award from the Michael Smith Foundation for Health Research and New Investigator Award from the Canadian Institutes of Health Research. J.A.A.-Z. is currently the British Columbia Lupus Society Scholar and holds a Scholar Award from the Michael Smith Foundation for Health Research. 


\section{REFERENCES}

1. Rees F, Doherty M, Grainge MJ, Lanyon P, Zhang W. The worldwide incidence and prevalence of systemic lupus erythematosus: a systematic review of epidemiological studies. Rheumatology. 2017 Nov 1;56(11):1945-61.

2. Eriksson C, Kokkonen H, Johansson M, Hallmans G, Wadell G, Rantapää-Dahlqvist S. Autoantibodies predate the onset of systemic lupus erythematosus in northern Sweden. Arthritis Res Ther. 2011;13(1):R30.

3. Arbuckle MR, McClain MT, Rubertone MV, Scofield RH, Dennis GJ, James JA, et al. Development of Autoantibodies before the Clinical Onset of Systemic Lupus Erythematosus. N Engl J Med. 2003 Oct 16;349(16):1526-33.

4. Alarcón GS, Mcgwin G, Roseman JM, Uribe A, Fessler BJ, Bastian HM, et al. Systemic lupus erythematosus in three ethnic groups. XIX. Natural history of the accrual of the American College of Rheumatology criteria prior to the occurrence of criteria diagnosis. Arthritis Care Res. 2004 Aug 15;51(4):609-15.

5. Ozbek S, Sert M, Paydas S, Soy M. Delay in the diagnosis of SLE: the importance of arthritis/arthralgia as the initial symptom. Acta Med Okayama. 2003 Aug;57(4):187-90.

6. Tan EM, Cohen AS, Fries JF, Masi AT, McShane DJ, Rothfield NF, et al. The 1982 revised criteria for the classification of systemic lupus erythematosus. Arthritis Rheum. 1982 Nov;25(11):1271-7.

7. Doria A, Zen M, Canova M, Bettio S, Bassi N, Nalotto L, et al. SLE diagnosis and treatment: When early is early. Autoimmun Rev. 2010 Nov;10(1):55-60.

8. Bartels CM, Buhr KA, Goldberg JW, Bell CL, Visekruna M, Nekkanti S, et al. Mortality and Cardiovascular Burden of Systemic Lupus Erythematosus in a US Population-based Cohort. J Rheumatol. 2014 Apr 1;41(4):680-7.

9. Zhang S, Su J, Li X, Zhang X, Liu S, Wu L, et al. Chinese SLE Treatment and Research group (CSTAR) registry: V. gender impact on Chinese patients with systemic lupus erythematosus. Lupus. 2015 Oct;24(12):1267-75.

10. Hwang J, Lee J, Ahn JK, Park E-J, Cha H-S, Koh E-M. Clinical characteristics of male and female Korean patients with systemic lupus erythematosus: a comparative study. Korean J Intern Med. 2015 Mar;30(2):242-9.

11. Canora J, García M, Mitjavila F, Espinosa G, Suárez S, González-León R, et al. Clinical characteristics during diagnosis of a prospective cohort of patients with systemic lupus erythematosus treated in Spanish Departments of Internal Medicine: The RELES study. Rev Clínica Esp Engl Ed. 2017 Jan;217(1):7-14.

12. Nossent J, Kiss E, Rozman B, Pokorny G, Vlachoyiannopoulos P, Olesinska M, et al. Disease activity and damage accrual during the early disease course in a multinational 
inception cohort of patients with systemic lupus erythematosus. Lupus. 2010 Jul;19(8):949_ 56.

13. Carls G, Li T, Panopalis P, Wang S, Mell AG, Gibson TB, et al. Direct and indirect costs to employers of patients with systemic lupus erythematosus with and without nephritis. J Occup Environ Med Am Coll Occup Environ Med. 2009 Jan;51(1):66-79.

14. Li T, Carls GS, Panopalis P, Wang S, Gibson TB, Goetzel RZ. Long-term medical costs and resource utilization in systemic lupus erythematosus and lupus nephritis: a five-year analysis of a large Medicaid population. Arthritis Rheum. 2009 Jun 15;61(6):755-63.

15. Furst DE, Clarke A, Fernandes AW, Bancroft T, Gajria K, Greth W, et al. Resource utilization and direct medical costs in adult systemic lupus erythematosus patients from a commercially insured population. Lupus. 2013 Mar;22(3):268-78.

16. Nightingale AL, Davidson JE, Molta CT, Kan HJ, McHugh NJ. Presentation of SLE in UK primary care using the Clinical Practice Research Datalink. Lupus Sci Med. 2017 Feb;4(1):e000172.

17. Rees F, Doherty M, Lanyon P, Davenport G, Riley RD, Zhang W, et al. Early Clinical Features in Systemic Lupus Erythematosus: Can They Be Used to Achieve Earlier Diagnosis? A Risk Prediction Model. Arthritis Care Res. 2017 Jun;69(6):833-41.

18. Lai N-S, Tsai T-Y, Koo M, Huang K-Y, Tung C-H, Lu M-C. Patterns of Ambulatory Medical Care Utilization and Rheumatologist Consultation Predating the Diagnosis of Systemic Lupus Erythematosus: A National Population-Based Study. Chopra A, editor. PLoS ONE. 2014 Jul 7;9(7):e101485.

19. Demas KL, Costenbader KH. Disparities in lupus care and outcomes: Curr Opin Rheumatol. 2009 Mar;21(2):102-9.

20. Andrade RM, Alarcón GS, Fernández M, Apte M, Vilá LM, Reveille JD, et al. Accelerated damage accrual among men with systemic lupus erythematosus: XLIV. Results from a multiethnic US cohort. Arthritis Rheum. 2007 Feb;56(2):622-30.

21. James JA, Kim-Howard XR, Bruner BF, Jonsson MK, McClain MT, Arbuckle MR, et al. Hydroxychloroquine sulfate treatment is associated with later onset of systemic lupus erythematosus. Lupus. 2007;16(6):401-9.

22. Choi MY, Barber MRW, Barber CEH, Clarke AE, Fritzler MJ. Preventing the development of SLE: identifying risk factors and proposing pathways for clinical care. Lupus. 2016 Jul;25(8):838-49.

23. British Columbia Ministry of Health [creator] (2013): Medical Services Plan (MSP) Payment Information File. Population Data BC [publisher]. Data Extract. MOH (2013). http://www.popdata.bc.ca/data. 
24. Canadian Institute for Health Information [creator] (2013): Discharge Abstract Database (Hospital Separations). Population Data BC [publisher]. Data Extract. MOH (2013). http://www.popdata.bc.ca/data.

25. British Columbia Ministry of Health [creator] (2013): Consolidation File (MSP Registration \& Premium Billing). Population Data BC [publisher]. Data Extract. MOH (2013). http://www.popdata.bc.ca/data.

26. BC Vital Statistics Agency [creator] (2012): Vital Statistics Deaths. Population Data BC [publisher]. Data Extract BC Vital Statistics Agency (2013). http://www.popdata.bc.ca/data.

27. BC Ministry of Health [creator] (2013): PharmaNet. BC Ministry of Health [publisher]. Data Extract. Data Stewardship Committee (2013). http://www.popdata.bc.ca/data.

28. Aviña-Zubieta JA, To F, Vostretsova K, De Vera M, Sayre EC, Esdaile JM. Risk of Myocardial Infarction and Stroke in Newly Diagnosed Systemic Lupus Erythematosus: A General Population-Based Study. Arthritis Care Res. 2017 Jun;69(6):849-56.

29. Rahman MM, Kopec JA, Sayre EC, Greidanus NV, Aghajanian J, Anis AH, et al. Effect of sociodemographic factors on surgical consultations and hip or knee replacements among patients with osteoarthritis in British Columbia, Canada. J Rheumatol. 2011 Mar;38(3):503-9.

30. Chen W, Lynd LD, FitzGerald JM, Sadatsafavi M. Influences of Socioeconomic Status on Costs of Asthma Under Universal Health Coverage: Med Care. 2016 Aug;54(8):789-95.

31. Hanly JG, Thompson K, Skedgel C. Identification of patients with systemic lupus erythematosus in administrative healthcare databases. Lupus. 2014 Nov;23(13):1377-82.

32. Guidance Document for the Costing of Health Care Resources in the Canadian Setting: 2nd Edition. Ottawa, ON: CADTH; 2016 Mar.

33. Romano PS, Roos LL, Jollis JG. Adapting a clinical comorbidity index for use with ICD-9CM administrative data: differing perspectives. J Clin Epidemiol. 1993 Oct;46(10):10751079; discussion 1081-1090.

34. Mihaylova B, Briggs A, O’Hagan A, Thompson SG. Review of statistical methods for analysing healthcare resources and costs. Health Econ. 2011 Aug;20(8):897-916.

35. Austin PC, Urbach DR. Using G-Computation to Estimate the Effect of Regionalization of Surgical Services on the Absolute Reduction in the Occurrence of Adverse Patient Outcomes: Med Care. 2013 Sep;51(9):797-805.

36. Lai N-S, Tsai T-Y, Li C-Y, Koo M, Yu C-L, Lu M-C. Increased Frequency and Costs of Ambulatory Medical Care Utilization Prior to the Diagnosis of Rheumatoid Arthritis: A National Population-Based Study. Arthritis Care Res. 2014 Mar;66(3):371-8. 
37. Kristensen LE, Jørgensen TS, Christensen R, Gudbergsen H, Dreyer L, Ballegaard C, et al. Societal costs and patients' experience of health inequities before and after diagnosis of psoriatic arthritis: a Danish cohort study. Ann Rheum Dis. 2017 Sep;76(9):1495-501.

38. Løppenthin K, Esbensen BA, Østergaard M, Ibsen R, Kjellberg J, Jennum P. Welfare costs in patients with rheumatoid arthritis and their partners compared with matched controls: a register-based study. Clin Rheumatol. 2017 Mar;36(3):517-25.

39. Rubinstein TB, Mowrey WB, Ilowite NT, Wahezi DM, for the CARRA Investigators. Delays to care in pediatric lupus patients from the Childhood Arthritis and Rheumatology Research Alliance Legacy Registry. Arthritis Care Res [Internet]. 2017 May 23; Available from: http://doi.wiley.com/10.1002/acr.23285

40. Murphy G, Isenberg D. Effect of gender on clinical presentation in systemic lupus erythematosus. Rheumatology. 2013 Dec 1;52(12):2108-15.

41. Riveros Frutos A, Casas I, Rúa-Figueroa I, López-Longo FJ, Calvo-Alén J, Galindo M, et al. Systemic lupus erythematosus in Spanish males: a study of the Spanish Rheumatology Society Lupus Registry (RELESSER) cohort. Lupus. 2017 Jun;26(7):698-706.

42. Tan TC, Fang H, Magder LS, Petri MA. Differences between Male and Female Systemic Lupus Erythematosus in a Multiethnic Population. J Rheumatol. 2012 Apr 1;39(4):759-69.

43. Pons-Estel GJ, Gonzalez LA, Zhang J, Burgos PI, Reveille JD, Vila LM, et al. Predictors of cardiovascular damage in patients with systemic lupus erythematosus: data from LUMINA (LXVIII), a multiethnic US cohort. Rheumatology. 2009 Jul 1;48(7):817-22.

44. Urowitz MB, Gladman DD, Anderson NM, Su J, Romero-Diaz J, Bae SC, et al. Cardiovascular events prior to or early after diagnosis of systemic lupus erythematosus in the systemic lupus international collaborating clinics cohort. Lupus Sci Med. 2016;3(1):e000143.

45. Maradit-Kremers H, Crowson CS, Nicola PJ, Ballman KV, Roger VL, Jacobsen SJ, et al. Increased unrecognized coronary heart disease and sudden deaths in rheumatoid arthritis: a population-based cohort study. Arthritis Rheum. 2005 Feb;52(2):402-11.

46. Pahau H, Brown MA, Paul S, Thomas R, Videm V. Cardiovascular disease is increased prior to onset of rheumatoid arthritis but not osteoarthritis: the population-based NordTrøndelag health study (HUNT). Arthritis Res Ther. 2014;16(2):R85.

47. Kokkonen H, Stenlund H, Rantapää-Dahlqvist S. Cardiovascular risk factors predate the onset of symptoms of rheumatoid arthritis: a nested case-control study. Arthritis Res Ther. 2017 Jun 30;19(1):148.

48. Lu M-C, Yan S-T, Yin W-Y, Koo M, Lai N-S. Risk of Rheumatoid Arthritis in Patients with Type 2 Diabetes: A Nationwide Population-Based Case-Control Study. Pietropaolo M, editor. PLoS ONE. 2014 Jul 2;9(7):e101528. 
49. Kasitanon N, Intaniwet T, Wangkaew S, Pantana S, Sukitawut W, Louthrenoo W. The clinically quiescent phase in early-diagnosed SLE patients: inception cohort study. Rheumatology. 2015 May 1;54(5):868-75.

50. Oglesby A, Korves C, Laliberté F, Dennis G, Rao S, Suthoff ED, et al. Impact of early versus late systemic lupus erythematosus diagnosis on clinical and economic outcomes. Appl Health Econ Health Policy. 2014 Apr;12(2):179-90. 
Table 1: Characteristics of individuals with and without SLE, overall and by sex

\begin{tabular}{|c|c|c|c|c|c|c|c|}
\hline & All SLE & All Non-SLE & $\begin{array}{l}\mathrm{p} \text {-value } \\
(\alpha=0.05)\end{array}$ & Female SLE & Male SLE & $\begin{array}{l}\text { Female Non- } \\
\text { SLE }\end{array}$ & $\begin{array}{l}\text { Male Non- } \\
\text { SLE }\end{array}$ \\
\hline $\mathrm{N}$ & 3,632 & 18,060 & - & 3,111 & 521 & 15,459 & 2,601 \\
\hline N (\%) Female & 3,111 (86\%) & 15,459 (86\%) & 0.93 & - & - & - & - \\
\hline $\begin{array}{r}\text { Mean (SD) Age } \\
\text { at Diagnosis }\end{array}$ & 49.6 (15.9) & $49.8(15.4)$ & 0.60 & $49.1(15.6)$ & $52.9(17.1)^{*}$ & $49.2(15.1)$ & $53.0(17.0)^{*}$ \\
\hline $\begin{array}{r}\text { Mean (SD) } \\
\text { Comorbidity } \\
\text { Score }\end{array}$ & $0.42(0.49)$ & $0.14(0.35) *$ & $<0.01$ & $0.40(0.49)$ & $0.50(0.50)^{*}$ & $0.13(0.34)$ & $0.17(0.37)^{*}$ \\
\hline $\begin{array}{r}\text { N (\%) Rural } \\
\text { Residence at } \\
\text { Diagnosis }\end{array}$ & 538 (15\%) & 2,108 (12\%)* & $<0.01$ & 459 (15\%) & 79 (15\%) & 1,784 (12\%) & $324(12 \%)$ \\
\hline $\begin{array}{l}\text { N (\%) with Full } \\
\text { Five-Years’ Post- } \\
\text { Index Follow-Up }\end{array}$ & 2,238 (62\%) & $12,935(72 \%)^{*}$ & $<0.01$ & 1,981 (64\%) & 257 (49\%)* & 11,177 (72\%) & $1,758(68 \%)^{*}$ \\
\hline
\end{tabular}




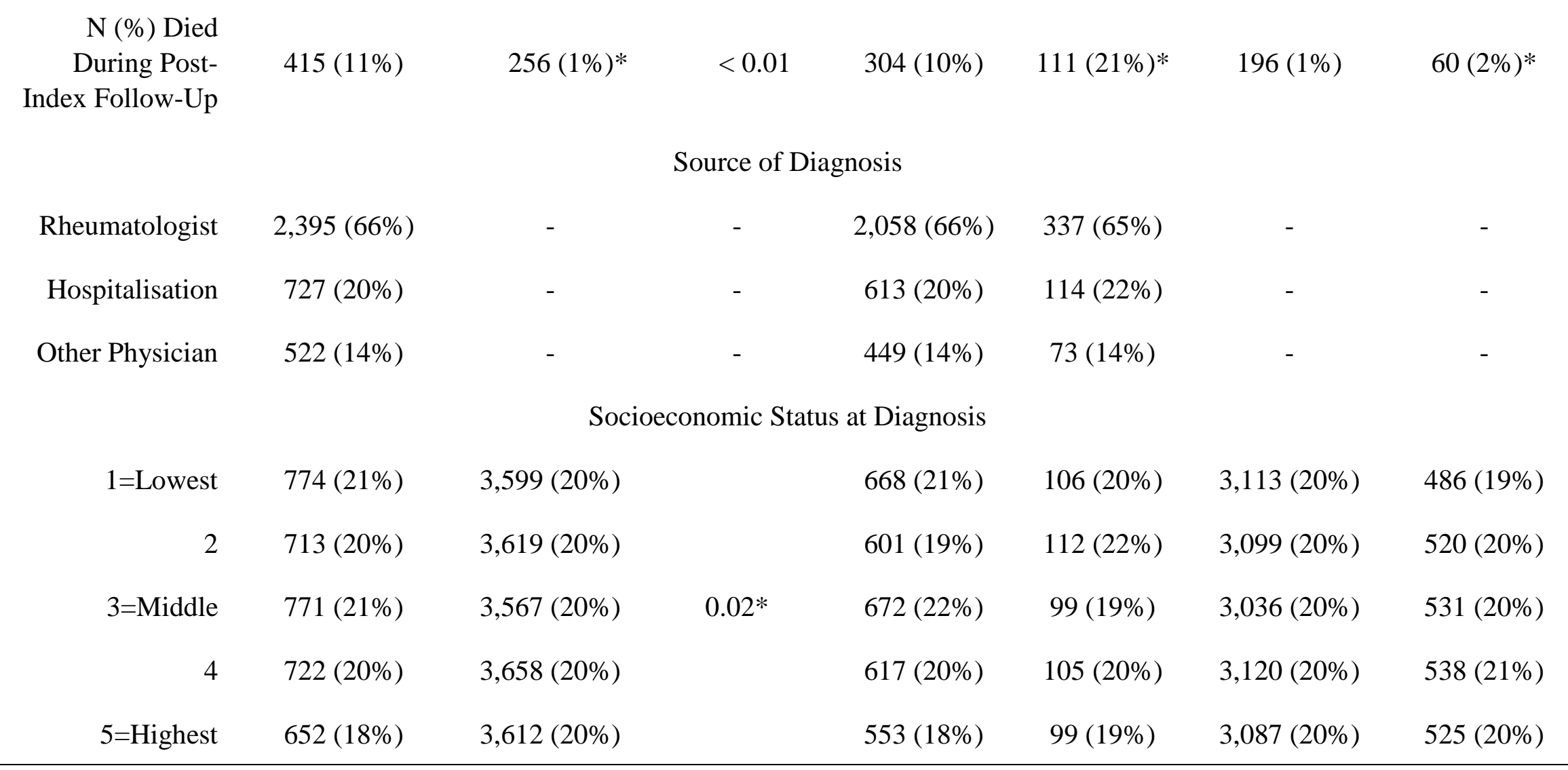

*statistically-significant difference between SLE and non-SLE (or females and males), at $\alpha=0.05$ 
Table 2: Overall Annual Mean Per-Person Direct Medical Costs, Before and After Adjustment

\begin{tabular}{|c|c|c|c|c|}
\hline $\begin{array}{l}\text { Year Before/After } \\
\text { Index Date }\end{array}$ & SLE & Non-SLE & $\begin{array}{l}\text { Unadjusted Incremental } \\
\text { Costs of SLE }\end{array}$ & $\begin{array}{l}\text { Adjusted Incremental } \\
\text { Costs }^{\mathrm{a}}(95 \% \mathrm{CI})\end{array}$ \\
\hline-5 & $\$ 3,073$ & $\$ 1,686$ & $\$ 1,386$ & $\begin{array}{c}\$ 1,131 \\
(\$ 592-\$ 2,657)\end{array}$ \\
\hline-4 & $\$ 3,416$ & $\$ 1,856$ & $\$ 1,560$ & $\begin{array}{c}\$ 1,316 \\
(\$ 658-\$ 3,309)\end{array}$ \\
\hline-3 & $\$ 3,682$ & $\$ 1,911$ & $\$ 1,771$ & $\begin{array}{c}\$ 1,536 \\
(\$ 754-\$ 4,017)\end{array}$ \\
\hline-2 & $\$ 4,409$ & $\$ 2,092$ & $\$ 2,317$ & $\begin{array}{c}\$ 2,015 \\
(\$ 986-\$ 4,941)\end{array}$ \\
\hline-1 & $\$ 6,111$ & $\$ 2,247$ & $\$ 3,864$ & $\begin{array}{c}\$ 3,473 \\
(\$ 1,661-\$ 8,666)\end{array}$ \\
\hline+1 & $\$ 12,019$ & $\$ 2,412$ & $\$ 9,607$ & $\begin{array}{c}\$ 6,474 \\
(\$ 3,220-\$ 15,437)\end{array}$ \\
\hline
\end{tabular}

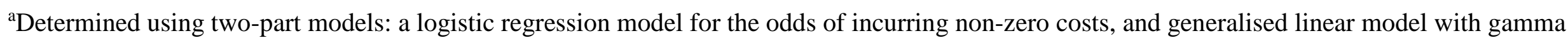
distribution and log-link predicting costs for those with non-zero costs; adjusted for age, sex, previous year’s modified Charlson comorbidity score, urban/rural residence and neighbourhood socioeconomic status

95\% CI=95\% credible interval 
Table 3: Adjusted Cost and Utilisation Ratios (95\% CI) Associated with SLE Status

Outpatient Medications

Year

Before/After

Diagnosis/

Index Date

$\begin{array}{lccc}\text { Overall Costs }^{\mathrm{a}} & \text { Outpatient } & & \text { Dispensed } \\ & \text { Encounters }^{\mathrm{b}} & \text { Outpatient Costs }^{\mathrm{a}} & \text { Prescription } \\ & & \text { Medications }^{\mathrm{b}}\end{array}$

Inpatient Hospitalisations

Inpatient Hospitalisation

$\begin{array}{cc}\text { Medication } & \text { Odds of Inpatient } \\ \text { Costs }^{\mathrm{a}} & \text { Hospitalisation }^{\mathrm{c}}\end{array}$

Medication Odds of Inpatient

Hospitalisation
Costs

(among those with non-

zero costs) ${ }^{\mathrm{c}}$

\begin{tabular}{|c|c|c|c|c|c|c|c|}
\hline-5 & $1.62(1.55-1.69)$ & $1.44(1.40-1.48)$ & $1.61(1.56-1.67)$ & $1.48(1.42-1.55)$ & $1.56(1.48-1.63)$ & $1.51(1.33-1.72)$ & $1.11(1.01-1.23)$ \\
\hline-4 & 1.66 (1.59-1.73) & $1.46(1.41-1.50)$ & 1.64 (1.58-1.70) & $1.52(1.46-1.58)$ & $1.58(1.51-1.66)$ & 1.40 (1.24-1.59) & $1.25(1.14-1.36)$ \\
\hline-3 & $1.74(1.66-1.81)$ & $1.48(1.44-1.53)$ & $1.68(1.62-1.74)$ & $1.50(1.44-1.57)$ & $1.57(1.49-1.64)$ & $1.52(1.34-1.72)$ & $1.30(1.18-1.42)$ \\
\hline-2 & 1.89 (1.81-1.98) & 1.58 (1.54-1.63) & $1.81(1.75-1.88)$ & $1.67(1.60-1.74)$ & $1.72(1.64-1.80)$ & $1.66(1.48-1.87)$ & $1.38(1.26-1.52)$ \\
\hline-1 & $2.42(2.32-2.53)$ & 1.99 (1.94-2.05) & $2.40(2.31-2.48)$ & $1.71(1.64-1.78)$ & $1.72(1.65-1.80)$ & $2.62(2.35-2.91)$ & $1.39(1.27-1.52)$ \\
\hline+1 & $3.52(3.36-3.68)$ & $2.43(2.36-2.50)$ & $2.92(2.81-3.02)$ & $1.97(1.89-2.06)$ & $2.12(2.03-2.22)$ & $4.52(4.09-4.99)$ & $1.75(1.61-1.90)$ \\
\hline
\end{tabular}

*adjusted for age at diagnosis, sex, previous year's modified Charlson comorbidity score, urban/rural residence and neighbourhood socioeconomic group

All values are statistically-significant $(\alpha=0.05)$

a Determined using a generalised estimating equations (linear) model, with gamma distribution and log-link 
${ }^{\mathrm{b}}$ Determined using a generalised estimating equations (count) model, with negative binomial distribution

${ }^{c}$ Determined using two-part models: a logistic regression model for the odds of incurring non-zero costs, and generalised linear model with gamma distribution and log-link predicting costs for those with non-zero costs 
Table 4: Adjusted Cost and Utilisation Ratios (95\%) Associated with Sex and Socioeconomic Status, among SLE only

\begin{tabular}{|c|c|c|c|c|c|c|c|c|}
\hline \multirow[b]{2}{*}{$\begin{array}{c}\text { Year } \\
\text { Before/After } \\
\text { Diagnosis }\end{array}$} & \multirow[b]{2}{*}{$\begin{array}{c}\text { Independent } \\
\text { Variable }\end{array}$} & \multirow[b]{2}{*}{ Overall $^{\mathrm{a}}$} & \multicolumn{2}{|c|}{ Outpatient } & \multicolumn{2}{|c|}{ Medications } & \multicolumn{2}{|c|}{ Inpatient Hospitalisations } \\
\hline & & & $\begin{array}{c}\text { Outpatient } \\
\text { Encounters }^{\mathrm{b}}\end{array}$ & $\begin{array}{c}\text { Outpatient } \\
\text { Costs }^{\mathrm{a}}\end{array}$ & $\begin{array}{c}\text { Dispensed } \\
\text { Prescription } \\
\text { Medications }^{\mathrm{b}}\end{array}$ & $\begin{array}{l}\text { Medication } \\
\text { Costs }^{\mathrm{a}}\end{array}$ & $\begin{array}{c}\text { Odds of } \\
\text { Inpatient } \\
\text { Hospitalisation }^{\mathrm{c}}\end{array}$ & $\begin{array}{c}\text { Inpatient } \\
\text { Hospitalisation Costs } \\
\text { (among those with }^{\text {non-zero costs) }}{ }^{\mathrm{c}}\end{array}$ \\
\hline \multirow[t]{7}{*}{-5} & Male Sex & $1.02(0.91-1.14)$ & $0.83(0.77-0.90)$ & $0.85(0.77-0.93)$ & $0.87(0.79-0.97)$ & $1.20(1.06-1.35)$ & $1.24(0.92-1.68)$ & $0.97(0.76-1.23)$ \\
\hline & $\begin{array}{l}\text { Female Sex } \\
\text { (reference) }\end{array}$ & - & - & - & - & - & - & - \\
\hline & 1=Lowest SES & $1.08(0.96-1.22)$ & $1.04(0.96-1.13)$ & $1.04(0.94-1.15)$ & $1.15(1.03-1.29)$ & $1.03(0.91-1.17)$ & $1.16(0.83-1.62)$ & $1.06(0.81-1.40)$ \\
\hline & 2 & $1.02(0.90-1.15)$ & $1.05(0.97-1.14)$ & $1.03(0.93-1.13)$ & $1.25(1.12-1.40)$ & $1.01(0.89-1.15)$ & $0.95(0.67-1.36)$ & $1.12(0.84-1.49)$ \\
\hline & 3=Middle SES & $0.92(0.82-1.04)$ & $0.93(0.86-1.01)$ & $0.91(0.82-1.01)$ & $0.95(0.85-1.06)$ & $0.93(0.81-1.05)$ & $1.05(0.74-1.48)$ & $0.94(0.72-1.24)$ \\
\hline & 4 & $0.86(0.76-0.97)$ & $0.94(0.86-1.02)$ & $0.92(0.83-1.02)$ & $0.96(0.86-1.07)$ & $0.90(0.79-1.03)$ & $0.83(0.58-1.20)$ & $0.84(0.62-1.12)$ \\
\hline & $\begin{array}{r}5=\text { Highest SES } \\
\text { (reference) }\end{array}$ & - & - & - & - & - & - & - \\
\hline \multirow[t]{7}{*}{-4} & Male Sex & $1.12(1.00-1.25)$ & $0.86(0.80-0.93)$ & $0.93(0.84-1.02)$ & $0.83(0.75-0.92)$ & $1.16(1.03-1.31)$ & $1.25(0.93-1.67)$ & $1.25(0.99-1.58)$ \\
\hline & $\begin{array}{l}\text { Female Sex } \\
\text { (reference) }\end{array}$ & - & - & - & - & - & - & - \\
\hline & 1=Lowest SES & $1.34(1.19-1.51)$ & $1.13(1.04-1.22)$ & $1.13(1.03-1.25)$ & $1.55(1.38-1.73)$ & $1.34(1.18-1.52)$ & $1.37(0.97-1.96)$ & $1.11(0.83-1.49)$ \\
\hline & 2 & $1.12(1.00-1.26)$ & $1.05(0.97-1.14)$ & $1.03(0.93-1.13)$ & $1.23(1.10-1.38)$ & $1.08(0.95-1.23)$ & $1.50(1.06-2.14)$ & $0.96(0.72-1.28)$ \\
\hline & 3=Middle SES & $1.01(0.90-1.14)$ & $0.96(0.89-1.04)$ & $0.93(0.84-1.03)$ & $1.13(1.01-1.26)$ & $1.07(0.94-1.22)$ & $1.23(0.86-1.77)$ & $0.91(0.67-1.22)$ \\
\hline & 4 & $1.18(1.04-1.33)$ & $1.06(0.97-1.15)$ & $1.07(0.97-1.19)$ & $1.28(1.14-1.43)$ & $1.07(0.94-1.22)$ & 1.38 (0.96-1.98) & $1.08(0.80-1.47)$ \\
\hline & $\begin{array}{r}5=\text { Highest SES } \\
\text { (reference) }\end{array}$ & - & - & - & - & - & - & - \\
\hline \multirow[t]{2}{*}{-3} & Male Sex & $1.11(0.99-1.24)$ & $0.86(0.80-0.93)$ & $0.91(0.83-1.00)$ & $0.84(0.75-0.93)$ & $1.09(0.97-1.23)$ & $1.08(0.80-1.46)$ & $1.61(1.24-2.09)$ \\
\hline & $\begin{array}{l}\text { Female Sex } \\
\text { (reference) }\end{array}$ & - & - & - & - & - & - & - \\
\hline
\end{tabular}




\begin{tabular}{|c|c|c|c|c|c|c|c|c|}
\hline \multirow[b]{2}{*}{$\begin{array}{c}\text { Year } \\
\text { Before/After } \\
\text { Diagnosis }\end{array}$} & \multirow[b]{2}{*}{$\begin{array}{c}\text { Independent } \\
\text { Variable }\end{array}$} & \multirow[b]{2}{*}{ Overall $^{\mathrm{a}}$} & \multicolumn{2}{|c|}{ Outpatient } & \multicolumn{2}{|c|}{ Medications } & \multicolumn{2}{|c|}{ Inpatient Hospitalisations } \\
\hline & & & $\begin{array}{c}\text { Outpatient } \\
\text { Encounters }^{\mathrm{b}}\end{array}$ & $\begin{array}{c}\text { Outpatient } \\
\text { Costs }^{\mathrm{a}}\end{array}$ & $\begin{array}{c}\text { Dispensed } \\
\text { Prescription } \\
\text { Medications }^{\mathrm{b}}\end{array}$ & $\begin{array}{c}\text { Medication } \\
\text { Costs }^{\mathrm{a}}\end{array}$ & $\begin{array}{c}\text { Odds of } \\
\text { Inpatient } \\
\text { Hospitalisation }^{\mathrm{c}}\end{array}$ & $\begin{array}{c}\text { Inpatient } \\
\text { Hospitalisation Costs } \\
\text { (among those with }^{\text {non-zero costs) }}{ }^{\mathrm{C}}\end{array}$ \\
\hline & 1=Lowest SES & $1.03(0.91-1.16)$ & $1.07(0.98-1.16)$ & $1.02(0.92-1.13)$ & $1.34(1.19-1.49)$ & $1.19(1.05-1.35)$ & $0.95(0.69-1.33)$ & $0.83(0.63-1.08)$ \\
\hline & 2 & $0.83(0.74-0.94)$ & $1.01(0.93-1.10)$ & $0.95(0.85-1.05)$ & $1.18(1.05-1.33)$ & $1.05(0.92-1.20)$ & $0.80(0.57-1.13)$ & $0.64(0.48-0.86)$ \\
\hline & 3=Middle SES & $0.78(0.69-0.88)$ & $0.93(0.85-1.01)$ & $0.86(0.77-0.95)$ & $1.00(0.89-1.12)$ & $0.91(0.80-1.04)$ & $0.76(0.54-1.08)$ & $0.70(0.52-0.95)$ \\
\hline & 4 & $0.92(0.82-1.04)$ & $1.03(0.95-1.12)$ & $1.00(0.90-1.10)$ & $1.09(0.97-1.22)$ & $1.00(0.88-1.14)$ & $1.03(0.74-1.44)$ & $0.81(0.61-1.08)$ \\
\hline & $\begin{array}{r}5=\text { Highest SES } \\
\text { (reference) }\end{array}$ & - & - & - & - & - & - & - \\
\hline \multirow[t]{7}{*}{-2} & Male Sex & $1.15(1.02-1.28)$ & $0.88(0.82-0.95)$ & $0.91(0.83-1.00)$ & $0.80(0.72-0.89)$ & $1.13(1.01-1.28)$ & $1.15(0.87-1.51)$ & 1.48 (1.16-1.89) \\
\hline & $\begin{array}{l}\text { Female Sex } \\
\text { (reference) }\end{array}$ & - & - & - & - & - & - & - \\
\hline & 1=Lowest SES & $1.16(1.03-1.30)$ & $1.15(1.07-1.25)$ & $1.15(1.04-1.26)$ & $1.34(1.20-1.51)$ & $1.07(0.94-1.21)$ & $1.25(0.92-1.71)$ & $1.09(0.83-1.43)$ \\
\hline & 2 & $1.15(1.02-1.30)$ & $1.12(1.03-1.21)$ & $1.09(0.99-1.21)$ & $1.33(1.18-1.49)$ & $0.88(0.77-1.00)$ & $1.26(0.92-1.74)$ & $1.28(0.97-1.69)$ \\
\hline & 3=Middle SES & $0.94(0.83-1.06)$ & $0.97(0.89-1.04)$ & $0.91(0.83-1.01)$ & $0.96(0.85-1.07)$ & $0.83(0.73-0.95)$ & $0.92(0.66-1.29)$ & $1.21(0.90-1.64)$ \\
\hline & 4 & $1.07(0.95-1.21)$ & $1.08(0.99-1.16)$ & $1.08(0.98-1.19)$ & $1.08(0.96-1.21)$ & $0.88(0.78-1.00)$ & $1.00(0.72-1.39)$ & $1.54(1.14-2.06)$ \\
\hline & $\begin{array}{r}5=\text { Highest SES } \\
\text { (reference) }\end{array}$ & - & - & - & - & - & - & - \\
\hline \multirow[t]{5}{*}{-1} & Male Sex & $1.24(1.12-1.37)$ & $0.99(0.93-1.05)$ & $1.07(0.99-1.15)$ & $0.82(0.74-0.90)$ & $0.99(0.89-1.10)$ & 1.49 (1.19-1.88) & $1.05(0.87-1.28)$ \\
\hline & $\begin{array}{l}\text { Female Sex } \\
\text { (reference) }\end{array}$ & - & - & - & - & - & - & - \\
\hline & 1=Lowest SES & $1.16(1.04-1.29)$ & $1.16(1.09-1.25)$ & $1.11(1.02-1.21)$ & $1.53(1.38-1.71)$ & $1.12(1.00-1.26)$ & $1.17(0.90-1.53)$ & $1.12(0.89-1.41)$ \\
\hline & 2 & $1.12(1.00-1.25)$ & $1.14(1.06-1.22)$ & $1.09(1.00-1.18)$ & $1.46(1.31-1.63)$ & $1.05(0.93-1.18)$ & $1.05(0.80-1.38)$ & $1.25(0.98-1.58)$ \\
\hline & 3=Middle SES & $0.88(0.79-0.98)$ & $1.02(0.95-1.09)$ & $0.96(0.89-1.04)$ & $1.12(1.00-1.25)$ & $0.96(0.85-1.08)$ & $0.81(0.61-1.07)$ & $0.98(0.76-1.26)$ \\
\hline
\end{tabular}




\begin{tabular}{|c|c|c|c|c|c|c|c|c|}
\hline \multirow[b]{2}{*}{$\begin{array}{c}\text { Year } \\
\text { Before/After } \\
\text { Diagnosis }\end{array}$} & \multirow[b]{2}{*}{$\begin{array}{c}\text { Independent } \\
\text { Variable }\end{array}$} & \multirow[b]{2}{*}{ Overall $^{\mathrm{a}}$} & \multicolumn{2}{|c|}{ Outpatient } & \multicolumn{2}{|c|}{ Medications } & \multicolumn{2}{|c|}{ Inpatient Hospitalisations } \\
\hline & & & $\begin{array}{l}\text { Outpatient } \\
\text { Encounters }^{\mathrm{b}}\end{array}$ & $\begin{array}{c}\text { Outpatient } \\
\text { Costs }^{\mathrm{a}}\end{array}$ & $\begin{array}{c}\text { Dispensed } \\
\text { Prescription } \\
\text { Medications }^{\mathrm{b}}\end{array}$ & $\begin{array}{c}\text { Medication } \\
\text { Costs }^{\mathrm{a}}\end{array}$ & $\begin{array}{c}\text { Odds of } \\
\text { Inpatient } \\
\text { Hospitalisation }^{\mathrm{c}}\end{array}$ & $\begin{array}{c}\text { Inpatient } \\
\text { Hospitalisation Costs } \\
\text { (among those with }^{\text {non-zero costs) }}{ }^{\mathrm{C}}\end{array}$ \\
\hline \multirow{9}{*}{+1} & 4 & $0.92(0.82-1.03)$ & $1.01(0.94-1.08)$ & $0.96(0.89-1.05)$ & $1.17(1.04-1.30)$ & $0.95(0.84-1.07)$ & $0.85(0.64-1.14)$ & $1.18(0.91-1.53)$ \\
\hline & $\begin{array}{r}5=\text { Highest SES } \\
\text { (reference) }\end{array}$ & - & - & - & - & - & - & - \\
\hline & Male Sex & $1.24(1.11-1.38)$ & $1.13(1.06-1.21)$ & $1.08(1.00-1.16)$ & $0.92(0.83-1.01)$ & $1.18(1.06-1.32)$ & $1.11(0.89-1.37)$ & $1.37(1.13-1.64)$ \\
\hline & $\begin{array}{l}\text { Female Sex } \\
\text { (reference) }\end{array}$ & - & - & - & - & - & - & - \\
\hline & 1=Lowest SES & $1.25(1.11-1.42)$ & $1.15(1.06-1.24)$ & $1.11(1.02-1.20)$ & 1.55 (1.39-1.73) & $1.10(0.97-1.24)$ & $1.68(1.31-2.14)$ & $0.97(0.79-1.20)$ \\
\hline & 2 & $1.19(1.05-1.35)$ & $1.14(1.05-1.23)$ & $1.11(1.02-1.21)$ & 1.42 (1.27-1.59) & $1.16(1.03-1.32)$ & $1.60(1.25-2.05)$ & $0.88(0.71-1.09)$ \\
\hline & 3=Middle SES & $0.89(0.79-1.01)$ & $0.95(0.88-1.03)$ & $0.94(0.87-1.02)$ & $1.04(0.93-1.15)$ & $0.95(0.84-1.07)$ & $1.07(0.83-1.37)$ & $0.78(0.62-0.98)$ \\
\hline & 4 & $0.98(0.87-1.11)$ & $1.01(0.93-1.09)$ & $1.07(0.98-1.16)$ & $1.13(1.01-1.26)$ & $0.94(0.83-1.06)$ & $1.16(0.90-1.49)$ & $0.81(0.65-1.02)$ \\
\hline & $\begin{array}{r}5=\text { Highest SES } \\
\text { (reference) }\end{array}$ & - & - & - & - & - & - & - \\
\hline
\end{tabular}

*adjusted for age at diagnosis, previous year's modified Charlson comorbidity score, and urban/rural residence

Bold values are statistically-significant $(\alpha=0.05)$

a Determined using a generalised estimating equations (linear) model, with gamma distribution and log-link

${ }^{\mathrm{b}}$ Determined using a generalised estimating equations (count) model, with negative binomial distribution

'Determined using two-part models: a logistic regression model for the odds of incurring non-zero costs, and generalised linear model

with gamma distribution and log-link predicting costs for those with non-zero costs 


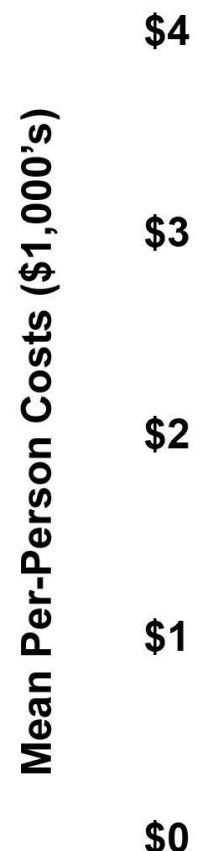

\begin{tabular}{|ll|}
\hline SLE: Outpatient & SLE: Medications \\
- non-SLE: Outpatient & non-SLE: Medications \\
\hline
\end{tabular}

$\$ 0$

$-5$

$-4$

$-3$

$-2$

$-1$

$+1$

Year Before/After Diagnosis 


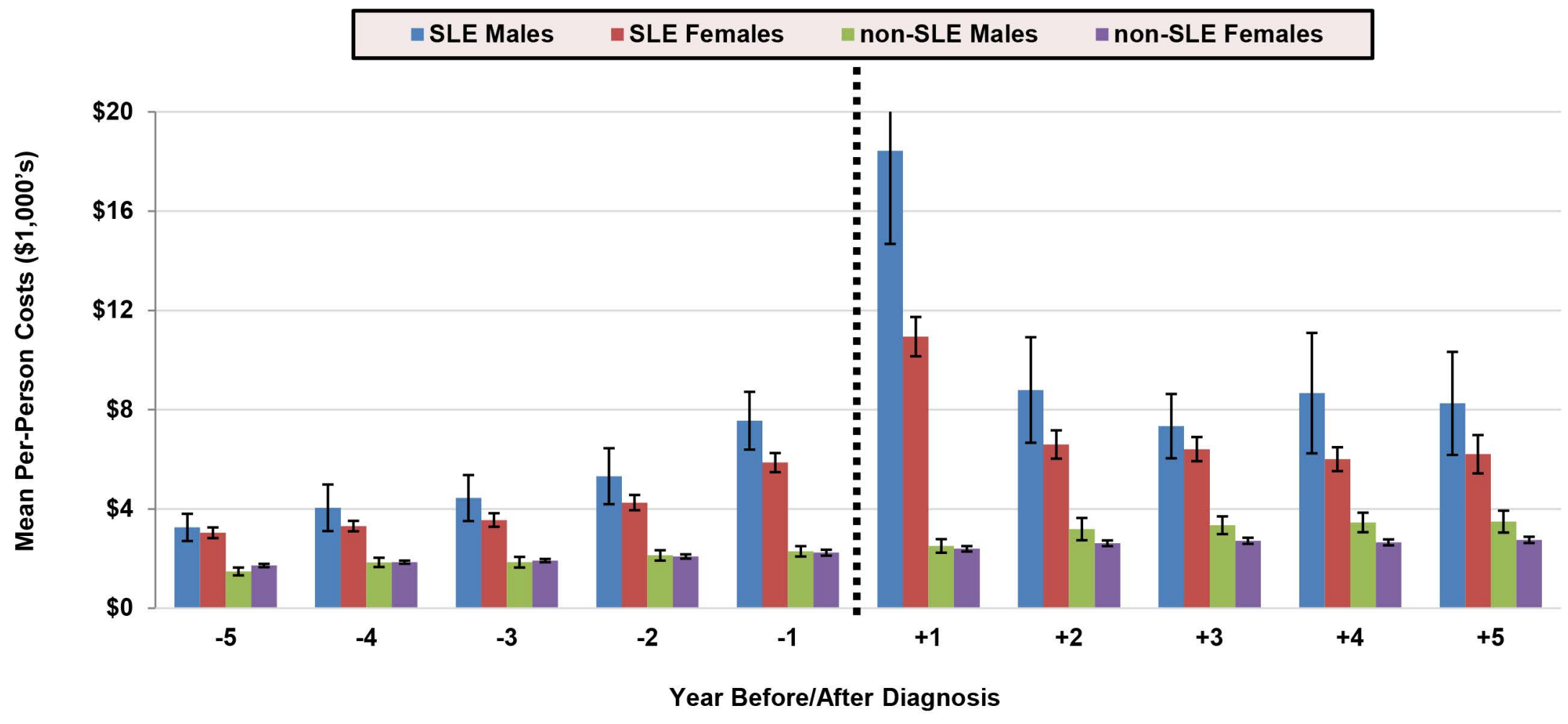

